\title{
Characterisation of post-pneumonectomy lung growth in adult mice
}

\author{
R. Voswinckel*, V. Motej"*, A. Fehrenbach", M. Wegmann", T. Mehling*, H. Fehrenbach", W. Seeger*
}

Characterisation of post-pneumonectomy lung growth in adult mice. R. Voswinckel, V. Motejl, A. Fehrenbach, M. Wegmann, T. Mehling, H. Fehrenbach, W. Seeger. (C) ERS Journals Ltd 2004.

ABSTRACT: A model of inducible expansion of the gas exchange area in adult mice would be ideal for the investigation of molecular determinants of airspace regeneration in vivo. Therefore, the post-pneumonectomy (post-PNX) compensatory lung growth in adult C57BL/6 mice was characterised in this study.

Mice underwent left-sided PNX. Right lung volume was assessed on days 1, 3, 5, 7, 10 and 21 after PNX, and total DNA and cellular proliferation of the right lung were determined. Lung histology was studied using immunohistochemistry and quantitatively characterised by detailed stereological investigations. Pulmonary function was assessed using a mouse body-plethysmograph.

Following PNX, right-lung volume rapidly restored the initial volume of left and right lung. Total DNA increased significantly over 21 days and equalled the total DNA amount of both lungs in the control mice. Septal cell proliferation significantly increased after PNX, and included endothelial cells, epithelial cells, smooth muscle cells and fibroblasts. Stereological investigations of left and right control lungs versus right lungs 21 days after PNX indicated complete restoration of body mass-specific alveolar surface area. Pulmonary function testing showed marked alteration at 3 days and normalisation at 21 days post-PNX.

In conclusion, well reproducible reconstitution of alveolar gas-exchange surface based on septal tissue expansion may be provoked by pneumonectomy in adult mice. Eur Respir J 2004; 24: 524-532.

\begin{abstract}
*Dept of Internal Medicine, University of Giessen, Giessen, and ${ }^{\#}$ Clinical Research Group "Chronic Airway Diseases", Dept of Internal Medicine, Philipps University Marburg, and Dept of Clinical Chemistry and Molecular Diagnostics, Philipps-University Marburg, Marburg, Germany.
\end{abstract}

Correspondence: R. Voswinckel, Dept of Internal Medicine, University of Giessen, Giessen, Germany.

Fax: 496419942568

E-mail: robert.voswinckel@innere.med.unigiessen.de

Keywords: Alveolarisation

lung development

pneumonectomy

pulmonary alveoli

regeneration

Received: January 142004

Accepted after revision: June 52004

This study was partially funded by the German Research Foundation.
Several pulmonary diseases originate from or are deteriorated by the loss of alveolar septae or, alternatively, remodelling processes of the septal walls, which result in severely compromised gas exchange within the alveoli. The principal ability of mammals to completely restore lung function after major losses of lung tissue by compensatory development of additional gas-exchange surface areas provides a rationale for identifying intrinsic regenerative programmes of the lung that may be employed for therapeutic purposes.

The molecular basis of alveolar generation and alveolar remodelling is presently not well understood [1]. Furthermore, the cellular components which contribute to repair and remodelling of pulmonary tissue still await ultimate elucidation. Solutions to the problems concerning repair and regeneration of lung tissue for restoration of functional alveoli are at the cutting edge of identifying novel therapeutic options for lung diseases like chronic obstructive pulmonary disease (COPD) and fibrosis.

It has been previously reported that partial resection of the lung results in a rapid compensatory growth process of the remaining lung tissue, restoring normal lung volume, cell mass and organ function, in a variety of mammalian species [2-6]. Compensatory lung growth following unilateral pneumonectomy (PNX) has been documented for dogs, rabbits, ferrets, rats and mice. However, it has been most extensively studied in rats, and the time course, volumetric and morphological changes are well characterised in this species $[7,8]$. Immature dogs show complete restoration of tissue loss after PNX [9, 10], whereas in mature dogs at least $55 \%$ of parenchyma has to be resected to evoke post-PNX lung growth [5]. Presently, much less detailed information is available for mice, although this species offers a wide spectrum of unique functional approaches in studies where genotypes are manipulated. To assure the suitability of adult mice for studying lung growth and alveolarisation as the basis for further functional investigations, the current authors investigated the time course and quantity of lung growth as well as the morphology after resection of the left lung in C57BL/6 mice.

\section{Methods}

\section{Animal surgery}

All animal procedures were performed according to the guidelines of good animal experimental practice of the University of Giessen (Giessen, Germany) and were approved by the local authorities for animal experiments. The 12-16-week-old C57BL/6 mice were anaesthetised by a single i.p. injection of ketamine $\left(60 \mathrm{mg} \cdot \mathrm{kg}^{-1}\right)$ and xylazine $\left(2 \mathrm{mg} \cdot \mathrm{kg}^{-1}\right)$. The mice were orally intubated with a 21 -gauge atraumatic cannula and mechanically ventilated with a mouse ventilator (Hugo Sachs Elektronik, March-Hugstetten, Germany). The left thoracic wall was shaved and disinfected. An incision was performed in the fifth, left intercostal space and extended to the pleural cavity. The left lung was carefully 
lifted through the opening and the left main bronchus, in combination with the hilar pulmonary vessels, was ligated with $6 / 0$ silk. Afterwards, the lung was resected, and the thorax and skin closed with silk sutures. Mechanical ventilation was terminated at the onset of spontaneous breathing. Postoperative pain was treated with buprenorphin subcutaneously twice daily for $48 \mathrm{~h}$. Chow and water was provided ad libitum.

\section{Volume determination}

The volume of the right lung was determined before PNX (baseline value), and at days 1, 3, 5, 7, 10 and 21 after PNX ( $\mathrm{n}=8$ at each time point). The mice were heparinised by an i.p. injection of 500 units of heparin and then sacrificed. The thorax was opened and the trachea and pulmonary artery were cannulated. The lung was then inflated by intratracheal instillation of PBS with a constant hydrostatic pressure of $10 \mathrm{cmH}_{2} \mathrm{O}$ and perfusion-fixed with $4 \%$ paraformaldehyde via the pulmonary artery with a pressure of $20 \mathrm{cmH}_{2} \mathrm{O}$ for 30 min. Afterwards, the trachea was ligated, and the heart and lung were resected en bloc from the thorax and fixed in fresh fixative overnight at $4{ }^{\circ} \mathrm{C}$. The volume of lungs and single lobes was determined by fluid displacement [11].

\section{Bromo-desoxyuridine labelling}

To assess proliferation during the time of rapid lung volume increase, mice were fed bromo-desoxyuridine (BrdU) continuously via the drinking water over 10 days, starting on the day of the PNX (0.8 $\mathrm{mg} \mathrm{BrdU} \cdot \mathrm{mL}^{-1}$, $\mathrm{n}=3$ mice per group). Lungs were cryosectioned and stained with alkaline phosphatase-coupled anti-BrdU antibody developed with nitroblue tetrazolium/5-bromo-4-chloro-3-inodolyl phosphate and counterstained with neutral red. Representative tissue sections of each lung were photographed at 200-fold magnification, BrdU-positive and -negative nuclei were counted and the ratio of BrdU-positive nuclei was calculated.

\section{Immunofluorescent staining}

Paraffin sections of $3 \mu \mathrm{m}$ thickness were sectioned on a rotary microtome (Leica, Wetzlar, Germany). Tissues were deparaffinised and rehydrated, and immunofluorescent staining was performed as described previously [12]. Pairs of serial sections were stained for Ki67 and phenotypic cell antigens, respectively, which included: cytokeratin for airway and alveolar epithelial cells; surfactant proprotein B for alveolar epithelial type-2 cells; pecam-1 (CD31) for endothelial cells; $\alpha$-smooth muscle actin for smooth muscle cells; and vimentin for fibroblasts. For Ki67 staining, antigen retrieval was performed by heating the mixture at $120^{\circ} \mathrm{C}$ for $10 \mathrm{~min}$ in a 10 $\mathrm{mM}$ citrate buffer by means of a pressure cooker. The primary antibodies used were against: CD31 (Pharmingen, Hamburg, Germany), pan-cytokeratin, Ki67 (Dako, Hamburg, Germany), proSPB (Chemicon; Temecula, USA), $\alpha$-smooth muscle actin and vimentin (Sigma, Deisenhofen, Germany). Hoechst 33342 (Sigma) was used to stain nuclei of the Ki67 cells.

\section{Ventricular mass quotient}

The hearts of the mice 21 days after PNX $(n=5)$ and the hearts of control mice $(n=16)$ were dissected, left and right ventricles were air dried on glass slides for $48 \mathrm{~h}$ at $40^{\circ} \mathrm{C}$, then weighed, and right-to-left ventricular weight ratios were calculated.

\section{Preparation of the lungs for stereological studies}

Preparation of the lungs for stereological studies was done according to FEHRENBACH et al. [13]. In brief, after opening the thoracic cavity, fixation was performed by intratracheal instillation of a mixture of $4 \%$ paraformaldehyde and $0.1 \%$ glutardialdehyde in N-2 hydroxyethylpiperazine-N-2ethanesulphonic buffer at a hydrostatic pressure of $20 \mathrm{~cm}$ for $30 \mathrm{~min}$ ( $\mathrm{n}=5$ mice per group). After ligation of the trachea, the lungs were excised and stored in cold fixative over night. Immediately before sampling of the tissue slices, the absolute volumes of right and left lungs were determined by fluid displacement according to SCHERLE [11]. Systematic random sampling of the lung tissue was performed according to MiCHEL and CRUZ-ORIVE [14]. In brief, the organ was cut into 2-mm slices. After several buffer rinses, slices were postosmicated for $2 \mathrm{~h}$ with $1 \%$ osmium tetroxide and stained en bloc over night with half-saturated, aqueous uranyl acetate as described previously [13]. The tissue was dehydrated through a graded series of ethanol and embedded in methacrylate resin (Historesin; Leica). Methacrylate embedment was proven to avoid the technical bias by shrinkage (data not shown), which is regularly observed with paraffin-embedded material [15]. Semi-thin sections $(1 \mu \mathrm{m})$ were cut on a Leica RM 2165 rotary microtome (Leica) and stained for $30 \mathrm{~min}$ at $60^{\circ} \mathrm{C}$ with a mixture of methylene blue and Azur II (ratio of 2:1).

\section{Stereological studies}

One glycolmethacrylate section of every slice of each lung ( $\mathrm{n}=5$ mice per group) was used for quantitative histological analysis, and from each lung slice a representative collection of test fields were obtained by meander scanning. This ensured that the structural parameters recorded were representative of the whole organ. Point and intersection counting was performed in a two-level procedure by established stereological methods to determine volumetric parameters as well as the total alveolar surface area [16]. At the first level, volume fractions of nonparenchyma (comprising of lumen, wall, and tunica adventitia of airways and vessels) and parenchyma were determined at a primary magnification of $\times 308$. At the second level, volume fractions of alveolar duct airspace, alveolar airspace and alveolar septum were determined at a primary magnification of $\times 615$. Absolute volumes of the respective lung compartments were obtained by multiplication of the total lung volume with the respective volume fraction. In addition, mass-specific volumes (volumes normalised to animal body weight) were calculated to account for structural changes due to physiological postnatal growth processes during the experimental period. Total alveolar surface area was calculated by multiplication of the surface density of the alveolar septum (i.e. surface per unit volume of parenchyma) and the absolute parenchymal volume. The surface density of the alveolar septum was estimated from the sum of intersections of the test lines $(35.2 \mu \mathrm{m}$ of length, at a magnification of $\times 615$ ) with the alveolar septa and the sum of test points hitting parenchymal structures.

To further characterise the alveolar compartment, the point-sampled intercept method was used, which is an efficient and direct tool for measuring the volume-weighted mean particle volume from single isotropic uniform random sections [17]. As described previously [13], the volumeweighted mean volume of alveoli was estimated in a one-step 
procedure projecting a combined grid of points and intercepts in a random direction on each test field of each section. By measuring the length of the isotropic-test line passing through the sampling point(s) within the alveolar transect, the volume dimensions of the alveoli were determined. Following MASSARO and MASSARO [18], the alveolus was closed by drawing an imaginary line connecting the ends of the alveolar walls whenever the isotropic test line passed the alveolar opening. This parameter includes information on mean alveolar size and variations of alveolar size. The increase in volume-weighted mean volume of alveoli may, therefore, resemble larger alveoli as well as higher variation in size without change in mean alveolar size.

All stereological analyses were performed by means of a computer-based system (connected to an Olympus BH-2 microscope (Olympus, Planegg, Germany)).

\section{Determination of total lung DNA}

Total genomic DNA was isolated from the left and right lungs of nonoperated control $(n=5)$ and day 21 PNX $(n=5)$ mice as described previously [19]. The lungs were homogenised and subsequently digested overnight with proteinase $\mathrm{K}$. The DNA was extracted with phenol-chloroform-isoamylalcohol (ratio of 25:24:1), and precipitated in ethanol and ammoniumacetate. The DNA concentration was measured by spectrophotometry (optical density at $260 \mathrm{~nm}$ : OD 260). The ratio of OD 260/280 was $>1.8$ in all accepted measurements.

\section{Lung function testing}

For determination of lung function parameters (tidal volume, breathing frequency, inspiration time, expiration time, midexpiratory flow, peak expiratory flow), two groups of mice $(n=4)$ were pneumonectomised and investigated at day 3 and 21 after the operation. A third group of mice that had not been operated on but were of the same age served as the control $(n=4)$. The lung function testing was done with conscious mice in head-out body plethysmography, as described previously [20].

\section{Statistics}

Paired t-tests were employed when not stated differently. Statistical significance was accepted at $\mathrm{p}<0.05$.

\section{Results}

Surgical resection of the left mouse lung was followed by a rapid and complete restoration of the initial lung volume, due to compensatory growth of the four right lobes. Volume gain was significant already 1 day after the PNX and increased until day 21. The volume of the right lung after 21 days of compensatory lung growth, corrected for individual body weight (mass-specific volume), equalled the mass-specific total lung volume of left and right lungs of nonoperated mice of the same age (fig. 1). Thereby, the right lung expanded to $145 \%$ of the initial volume. In control mice, the left lung had a share of $30.6 \%$ of the total lung volume. The remaining lobes of the right lung after PNX increased disproportionately in volume, with the cardiac lobe displaying the strongest relative volume gain over 21 days (fig. 1 and table 1).

To elucidate whether this complete regeneration of organ volume was paralleled by an increase in lung tissue and,
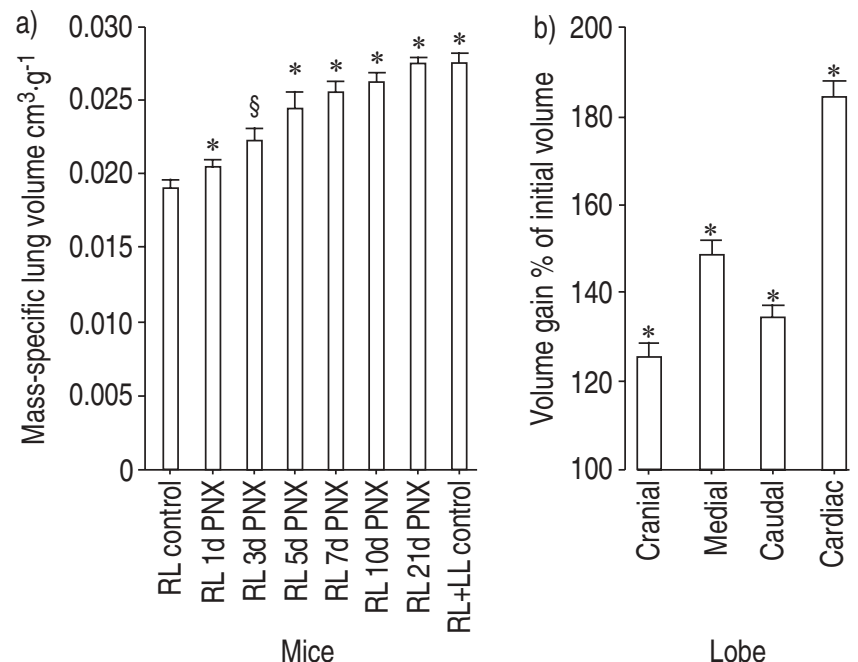

Fig. 1.-Quantity and kinetics of post-pneumonectomy (post-PNX) lung growth in mice. a) The volume of the right lung (RL) increased rapidly after left-sided pneumonectomy. The time course of lung growth leading to complete compensation of volume loss is shown. Lung volume was corrected for individual body weights. b) The four right lobes did not increase equally in volume over 21 days. The cardiac lobe showed the largest volume gain relative to its initial volume and the upper lobe the smallest ( $\mathrm{n}=8$ in all experiments). LL: left lung; xd PNX: $x$ days after PNX. Data are presented as mean \pm SEM. *: significant $(\mathrm{p}<0.05)$ volume increase compared with control or ${ }^{\S}$ : with control and preceding time point.

Table 1. - Volumetric data

\begin{tabular}{lccrr}
\hline Mass specific volumes & $\begin{array}{c}\text { Right lung } \\
\text { cranial lobe }\end{array}$ & $\begin{array}{c}\text { Right lung } \\
\text { medial lobe }\end{array}$ & $\begin{array}{c}\text { Right lung } \\
\text { caudal lobe }\end{array}$ & $\begin{array}{c}\text { Right lung } \\
\text { cardiac lobe }\end{array}$ \\
\hline${\text { Control } \mathrm{mm}^{3} \cdot \mathrm{g}^{-1}}_{\text {Control \% of total }}$ & $4.98 \pm 0.18$ & $3.41 \pm 0.12$ & $7.24 \pm 0.22$ & $3.43 \pm 0.12$ \\
Control \% of right lung & $18.13 \pm 0.39$ & $12.40 \pm 0.26$ & $26.37 \pm 0.34$ & $12.49 \pm 0.23$ \\
21d PNX mm ${ }^{3} \cdot \mathrm{g}^{-1}$ & $26.11 \pm 0.50$ & $17.88 \pm 0.36$ & $38.0 \pm 0.34$ & $18.01 \pm 0.36$ \\
21d PNX \% of right lung & $6.23 \pm 0.13$ & $5.06 \pm 0.16$ & $9.70 \pm 0.24$ & $6.33 \pm 0.19$ \\
Control versus 21d PNX p-value & $22.83 \pm 0.31$ & $18.50 \pm 0.42$ & $35.52 \pm 0.58$ & $23.15 \pm 0.37$ \\
& $<0.001$ & $<0.001$ & $<0.001$ & $<0.001$ \\
\hline
\end{tabular}

Determination of the volumes of the different lung lobes of mice before (control) and 21 days after left-sided pneumonectomy (21d PNX); As the four right lobes do not equally increase in volume during compensatory lung growth, their relative size changes; Mass specific volumes means lung volume per gram of body weight. Data are presented as mean \pm SEM (control $n=20 ; 21 \mathrm{~d}$ PNX $n=8)$. Statistics were done applying paired $t$-test for control and 21 days post PNX groups $\left(\mathrm{cm}^{3} \cdot \mathrm{g}^{-1}\right)$. 
consequently, in the growth of alveolar walls and formation of alveoli rather than by the mere distension of the airspaces, total lung DNA was determined and stereological studies were performed. Total DNA content of the right lung 21 days after left-sided PNX was significantly increased in comparison with the total DNA of the right control lungs, and equalled total DNA content of left and right lungs of nonoperated control mice (fig. 2a). Proliferation in alveolar septa during the first 10 days of compensatory lung growth was investigated by continuous feeding of BrdU over this time and subsequent BrdU-staining of the lungs. The proliferation index of septal cells was significantly increased in compensatory grown lungs and locally accentuated in subpleural areas (fig. 2b-d). Comparable results were obtained by staining for the proliferation antigen Ki67 in control lungs and lungs 7 days after PNX, showing dramatically increased proliferation activity at this time point (fig. 3). To further clarify which cell types proliferate at this time point, pairs of serial sections were stained for phenotypic cell antigens and Ki67, respectively. Specific staining was done for airway and alveolar epithelial cells (cytokeratin), for alveolar epithelial type-2 cells (proSPB), for endothelial cells (CD31), for smooth muscle cells ( $\alpha$-smooth muscle actin) and for fibroblasts (vimentin). It
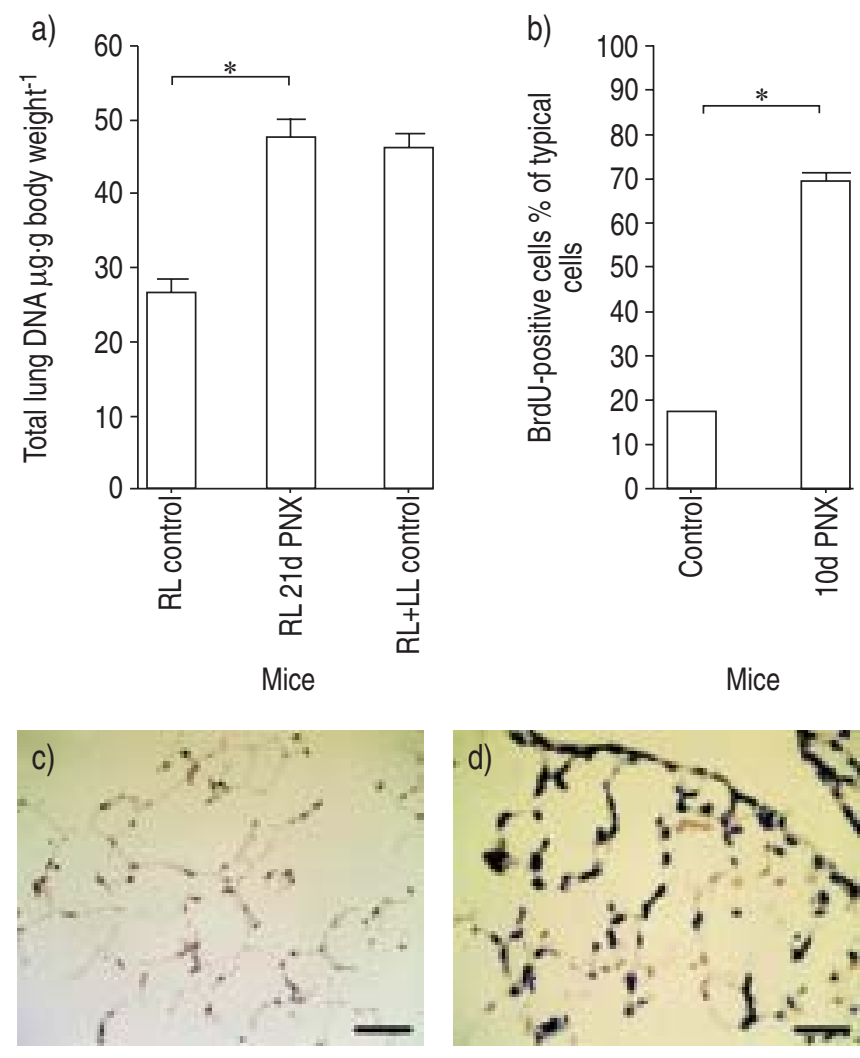

Fig. 2.-Measurement of total DNA mass (a) and cellular proliferation (b-d). a) The total DNA content of the right lung before pneumonectomy (RL control), right lung 21 days after left-sided pneumonectomy (RL 21d PNX), and right and left lung of nonoperated mice (RL+LL control, $n=5)$. The DNA mass of right lungs 21 days after pneumonectomy was significantly increased compared with right lungs from nonoperated mice, and equalled DNA mass of left and right lungs of nonoperated mice. b) Proliferation of septal cells over 10 days compensatory lung growth. Proliferating cells were labelled by continuous feeding of bromodesoxyuridine (BrdU), and visualised by specific antibody staining in nonoperated control mice (c) and pneumonectomised mice (d). Blue nuclear stain: BrdU positive; brown/red nuclear stain: BrdU negative, $\mathrm{n}=3$. Data are presented as mean \pm SEM $(*: \mathrm{p}<0.05)$. Scale bar $=50 \mu \mathrm{m}$. was demonstrated that all these cell compartments proliferate and thereby contribute to the post-PNX lung growth (fig. 4).

Stereological investigation of semi-thin sections (fig. 5a-f) revealed that the mass-specific parameters (normalised to individual body weight) for lung volume, alveolar surface area, parenchyma, nonparenchyma and airspaces were not significantly different in right lungs 21 days after PNX compared with left and right control lungs of nonoperated mice (table 2). The only significant difference observed was in the mass-specific volume of alveolar septa. Focal areas of thickened septa were observed in subpleural regions. MassonGoldner staining showed increased cellularity, rather than increased matrix deposition, in those thickened septa (fig. $5 \mathrm{~g}$, h). Notably, the volume-weighted mean alveolar volume was significantly larger $(\mathrm{p}<0.001)$ in the right lungs 21 days after PNX $\left(89.5 \pm 4.3 \times 10^{3} \mu^{-3}\right)$ in comparison with control lungs $\left(51.4 \pm 9 \times 10^{3} \mu \mathrm{m}^{-3}\right)$, an effect that was independent of body weight (data not shown). Although the absolute total airspace volume of alveoli was significantly larger $(\mathrm{p}=0.009)$ in right lungs 21 days after PNX $\left(453 \pm 19 \mathrm{~mm}^{3}\right)$ in comparison with left and right lung of nonoperated animals $\left(370 \pm 15 \mathrm{~mm}^{3}\right)$, the concomitant increase in the volumeweighted mean alveolar volume indicates that this was at least only partially achieved by the formation of new alveoli.

The ventricular mass quotient (right/left ventricular mass) was $0.27 \pm 0.01$ for control animals $(n=16)$ and $0.273 \pm 0.02$ for mice 21 days after PNX $(n=5)$.

To assess parameters of in vivo pulmonary function, head-out body plethysmography was performed on spontaneously breathing mice. The breathing frequency and tidal volumes of control mice and mice 21 days after PNX were similar, whereas breathing frequency was increased and tidal volume was decreased at 3 days after PNX. Furthermore, mid-expiratory airflow, a parameter for lung volume and bronchial resistance, was decreased 3 days after PNX but reached the control value 21 days after PNX (fig. 6).

\section{Discussion}

The compensatory lung growth of mice was investigated to evaluate if it can be used as a reliable model of inducible lung growth and alveolar wall formation in this species. Functional studies on compensatory lung growth in mice have already been carried out [19, 21, 22], but detailed analysis of the time frame and kinetics of lung growth, as well as stereological investigations for the quantification and proof of alveolar septal wall formation are still lacking. In contrast, detailed studies have been performed in rats and dogs [10, 23-25].

Compensatory lung growth has not been observed in adult humans. Children may show partial compensation of pulmonary parenchymal loss [26]. The transplantation of adult lung lobes into children results in a distension of the transplant during body growth, but not in compensatory growth of alveolar septa in the transplanted lung [27]. This might compare to compensatory lung growth following PNX in canines, which is restricted in adult dogs in that it only occurs after resection of $>50 \%$ of lung tissue [5]. In contrast, immature dogs seem to have the capacity of complete compensatory lung growth due to vigorous tissue gain and alveolarisation [10]. An age dependency of post-PNX lung growth has also been described for rabbits [28], but could not be demonstrated in rats [7].

The fact that reconstitution of lung parenchyma and gas exchange surface area can be triggered in different mammalian species, in both youth and adulthood, suggests the existence of intrinsic programmes that may regulate pulmonary maintenance, alveolar septal growth and alveolarisation. 

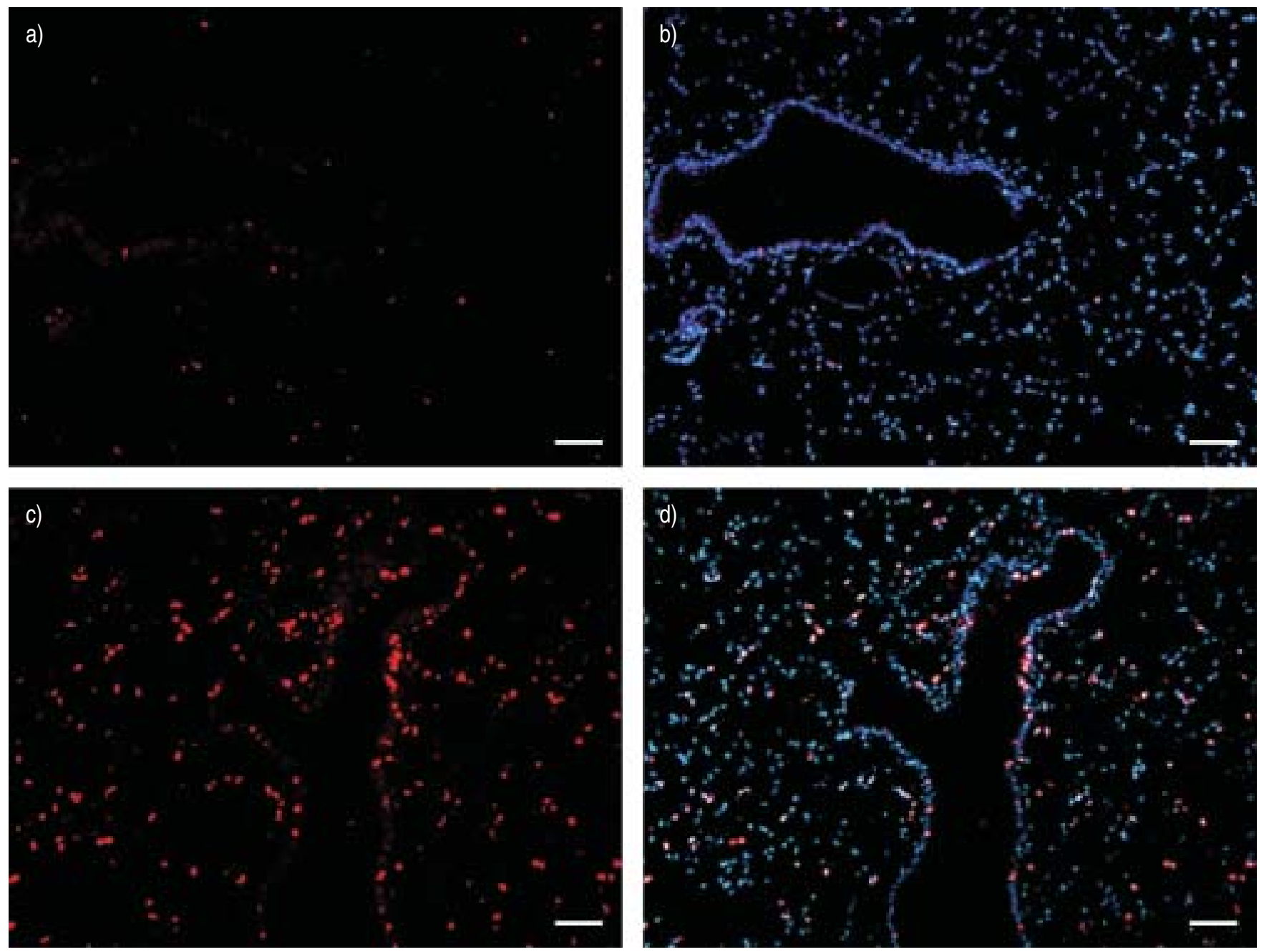

Fig. 3. - Proliferation of pulmonary cells 7 days after pneumonectomy (PNX). a, c) Nuclear staining for the proliferation antigen Ki67 (red), and b, d) the overlay of Ki67-staining and the nuclear dye Hoechst 33342 (blue). Massive increase of proliferation can be detected in the lung 7 days after PNX (c, d) when compared with lung tissue of nonoperated mice of the same age (a, b). Scale bar=100 $\mu \mathrm{m}$.

A review on this matter is given by BROWN et al. [1]. If these programmes could be identified, new therapeutic approaches to a variety of pulmonary diseases would be conceivable. In the era of in vivo genetic manipulation, the mouse is the ideal species for the investigation of such regenerative programmes of the lung.

In this study evidence is presented for rapid and complete restoration of lung volume in mice following PNX (fig. 1). Stereological investigations revealed that the volumes of airspace (of both alveolar ducts and alveoli) as well as the total gas exchange surface area did not significantly differ between controls and pneumonectomised animals 21 days after PNX. In this study, a significant difference for tissue volume of alveolar septa that was increased in the pneumonectomised mice was observed (table 2). This can be explained by the observation of areas with thickened and putatively not fully matured septa 21 days after PNX (fig. 5). These septa were comprised of densely packed cells rather than of extensive extracellular matrix deposition, which is in line with the assumption that these septa, after rapid proliferation of septal cells, still await further maturation and thinning. Interestingly, the volume-weighted mean alveolar volume was also significantly increased in the PNX group. This may represent an increase in alveolar size or a higher variation in alveolar size without increase of mean alveolar size. The classical stereological parameters determined in this study do not allow for a definite conclusion about the relative contribution of newly formed alveoli to the compensation of alveolar surface area, and, therefore, for the generation of new alveolar septa versus the growth of already existing septa. This will require the direct determination of the absolute number of alveoli by design-based stereological methods that have been developed in parallel to this study [29].

Lung functional parameters of tidal volume, breathing frequency and mid-expiratory airflow, measured in vivo, were markedly altered at 3 days after PNX and normalised by compensatory lung growth at 21 days after PNX, which indicates not only histological but also functional restoration.

A massive cellular proliferation must underlie the rapid generation of tissue in this model. Only very low basal levels of proliferation can be observed in nonoperated control lungs, whereas lung tissue 7 days post-PNX shows dramatically increased proliferation (fig. 3). Phenotypical characterisation of proliferating cells showed that all major cellular compartments participated in the proliferative process (fig. 4). Continuous labelling of proliferating cells over 10 days with BrdU revealed areas of BrdU-positive thickened septa in subpleural areas, which is in line with findings and with theoretical considerations suggesting subpleural and peribronchial regions for preferred lung growth [30]. A significantly higher rate of proliferation in subpleural regions 

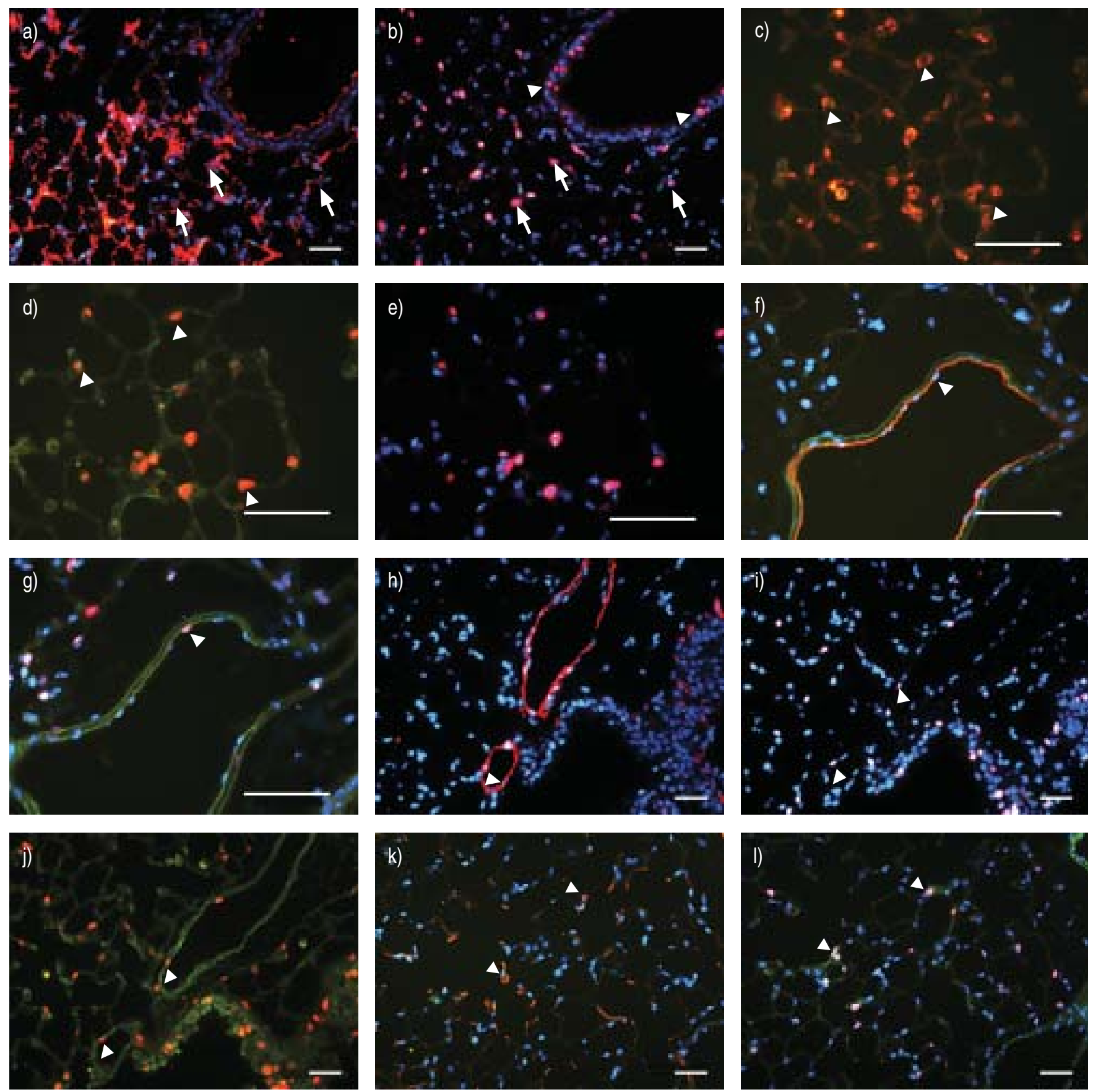

Fig. 4. - Phenotypical characterisation of proliferating cells in a lung 7 days after pneumonectomy. Serial sections stained red for the phenotypic markers cytokeratin (a), pro-SPB (c), pecam-1 (f), $\alpha$-smooth muscle actin (h), vimentin (k) and Ki67 (b, d, e, g, i, j, 1 ). Nuclear stain with Hoechst 3342 (blue) and tissue autofluorescence (green) are shown for better orientation where needed. Proliferation of bronchial epithelial cells (arrowheads) and alveolar epithelial cells (arrows) are shown in a) and b). Further specification for proliferating type II cells was done in c-e) (arrowheads). The figures f) and g) show a proliferating endothelial cell in a pulmonary artery (arrowheads). Proliferating smooth muscle cells in the media of a small pulmonary artery are visible in $\mathrm{h}-\mathrm{j}$ ) (arrowheads). Proliferating alveolar fibroblasts are shown in $\mathrm{k}$ ) and $\mathrm{l}$ ) (arrowheads). Scale bars $=100 \mu \mathrm{m}$.

compared with central areas of the lung were shown very recently in newborn dogs [23]. This poses the question "what is the main driving force for the post-PNX lung growth programme?". Although it was not the main focus of this study, the findings of preferred subpleural lung growth and preferred growth of the cardiac lobe directly neighbouring the newly formed cavity favour a major contribution of sensing of mechanical forces and mechanotransduction pathways as an underlying mechanism. This issue should be addressed in further studies. The ratio of right/left ventricular mass did not change after PNX, indicating absence of pulmonary hypertension.

In conclusion, this study shows that unilateral pneumonectomy of adult mice is followed by a rapid and complete compensatory growth of the remaining lung, which includes cellular proliferation and leads to restoration of an adequately sized alveolar surface area and respiratory function parameters. The lung volume and alveolar surface area reconstitution is completed at 21 days after pneumonectomy, although 

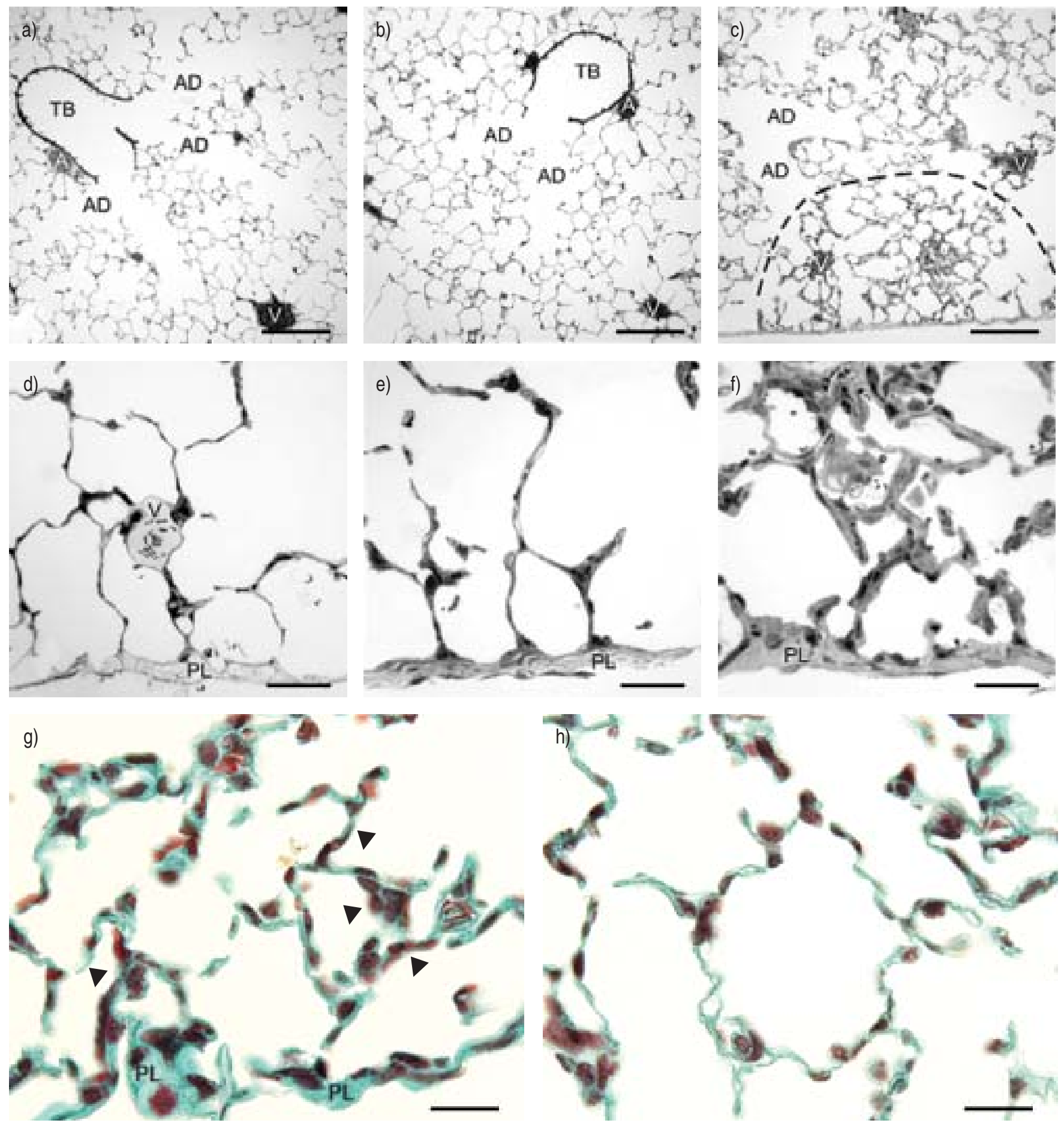

Fig. 5. - Light micrographs of nonoperated control lung (a, d) and of right lung 21 days after left lung pneumonectomy (PNX) (b, c, e, f, g, h) PNX- and age-matched control lungs exhibited similar microscopic appearance of terminal bronchioles, alveolar ducts and alveoli, particularly in central regions. Subpleural regions exhibited focal areas (c outlined by - - - - , and g) with thickened alveolar septa and increased cellularity, while closely adjacent regions (e, h) exhibited similar architecture as control lungs (d). Masson-Goldner staining for nuclei (red) and extracellular matrix (green) shows higher cellular density in thickened alveolar septa (arrowheads) rather than increased deposition of matrix material. A: arterial vessel; PL: pleura; V: venous vessel. Scale bars: $\mathrm{a}-\mathrm{c})=100 \mu \mathrm{m} ; \mathrm{d}-\mathrm{f})=33.3 \mu \mathrm{m}$; and $\mathrm{g}-\mathrm{h})=25 \mu \mathrm{m}$.

focal areas of the lung still show signs of septal immaturity. Proportional neo-alveolarisation could not be definitely proven in this study. Interestingly, the extent of growth response differs among the different lobes of the right lung, being largest in the cardiac lobe. This study in wildtype C57BL/6 mice provides a basis for future studies in genetically altered mice, which will allow questions about the intrinsic regulative pathways of lung growth to be addressed, which, in turn, could help to develop new therapeutic strategies leading to a successful induction of alveolarisation in adult mammals.

Acknowledgements. The authors wish to gratefully acknowledge the expert technical assistance of T. Rausch, N. Weisel and S. Lay. 
Table 2. - Stereological data

\begin{tabular}{lccc}
\hline Parameters & Control & PNX & Significance p-value \\
\hline Body weight g & $24.3 \pm 0.3$ & $28.0 \pm 0.7$ & 0.001 \\
Lung volume $\mathrm{mm}^{3}$ & $721 \pm 27$ & $857 \pm 25$ & 0.006 \\
Mass-specific volumes $\mathrm{mm}^{3} \cdot \mathrm{g}^{-1}$ & & & \\
$\quad$ Lung & $29.7 \pm 0.9$ & $30.6 \pm 0.9$ & $\mathrm{NS}$ \\
$\quad$ Nonparenchyma & $3.9 \pm 0.3$ & $4.0 \pm 0.2$ & $\mathrm{NS}$ \\
Parenchyma & $25.8 \pm 0.8$ & $26.6 \pm 0.8$ & $\mathrm{NS}$ \\
Airspace & $22.9 \pm 0.7$ & $23.1 \pm 0.7$ & $\mathrm{NS}$ \\
$\quad$ Alveoli & $15.2 \pm 0.5$ & $16.2 \pm 0.6$ & $\mathrm{NS}$ \\
$\quad$ Alveolar ducts & $7.7 \pm 0.4$ & $6.9 \pm 0.3$ & $\mathrm{NS}$ \\
$\quad$ Alveolar septa & $2.9 \pm 0.2$ & $3.6 \pm 0.1$ & 0.023 \\
Volume weighted mean alveolar volume $10^{3} \mu \mathrm{m}^{-3}$ & $51.4 \pm 1.9$ & $89.4 \pm 4.3$ & $<0.001$ \\
Total Sa cm & $410 \pm 13$ & $453 \pm 11$ & 0.033 \\
Mass-specific Sa $\mathrm{cm}^{2} \cdot \mathrm{g}^{-1}$ & $16.9 \pm 0.4$ & $16.2 \pm 0.3$ & $\mathrm{NS}$ \\
\hline
\end{tabular}

Data are presented as mean $\pm \operatorname{SEM}(\mathrm{n}=5)$. Stereological data of left and right lungs of nonoperated mice (control) and of right lungs only of mice 21 days after pneumonectomy (PNX); The mass specific lung volume, parenchymal volume and total alveolar surface area (Sa) are not significantly different between the two groups, indicating reconstitution of tissue and gas-exchange surface loss; Volume-weighted mean alveolar volume is significantly increased 21 days after PNX and suggests growth of existing alveoli rather than proportional neo-alveolarisation; The mass-specific volume of alveolar septa is increased in pneumonectomised mice, indicating a contribution of thickened septa to the newly built gas exchange surface.
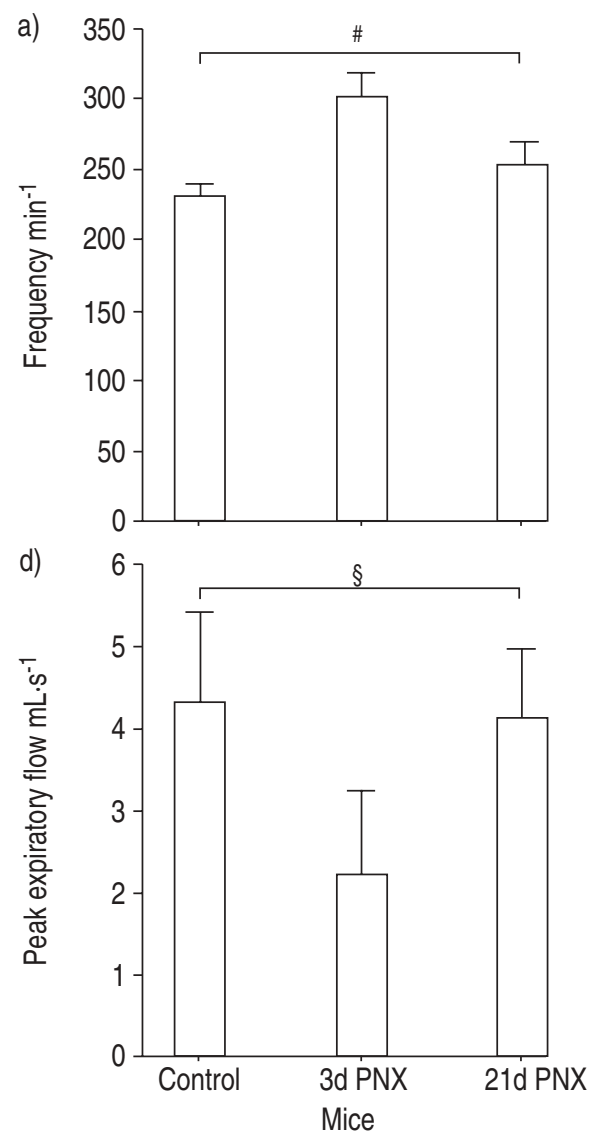
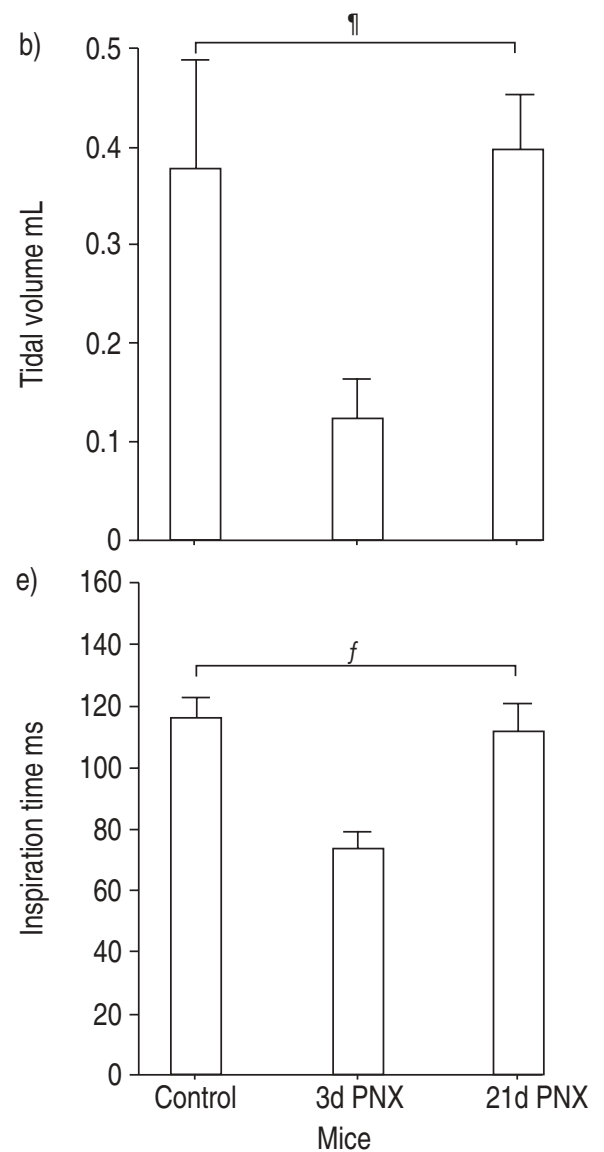
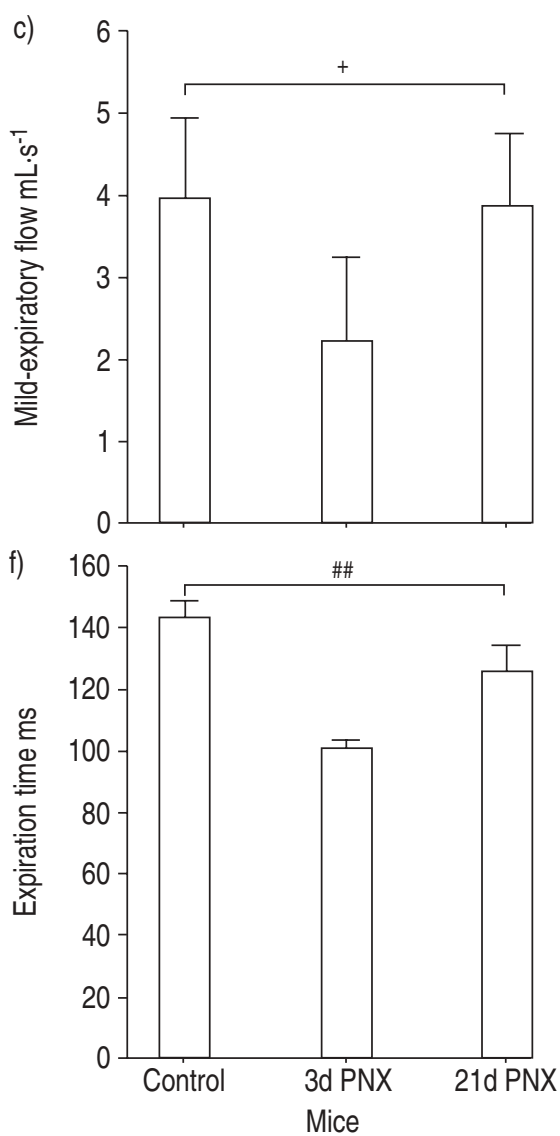

Fig. 6. - Lung function testing of spontaneously breathing mice before (control), and 3 and 21 days after pneumonectomy (3d and 21d PNX, respectively). At 3 days post-PNX, all parameters indicated an alteration of lung function due to tissue loss with increased breathing frequency, decreased tidal volume, airflow parameters, and inspiratory and expiratory times. At 21 days following pneumonectomy, the parameters returned to the initial values. Data are presented as mean \pm SEM $(n=4)$. For statistical significance, analysis of variance was performed; ${ }^{\#}: 0.023 ;{ }^{?}: 0.055$; ${ }^{+}: 0.375 ;{ }^{\S}: 0.356 ;{ }^{f}: 0.004{ }^{\# \#}: 0.002$.

\section{References}

1. Brown LM, Rannels SR, Rannels DE. Implications of postpneumonectomy compensatory lung growth in pulmonary physiology and disease. Respir Res 2001; 2: 340-347.

2. Langston C, Sachdeva P, Cowan MJ, Haines J, Crystal RG,
Thurlbeck WM. Alveolar multiplication in the contralateral lung after unilateral pneumonectomy in the rabbit. Am Rev Respir Dis 1977; 115: 7-13.

3. McBride JT. Lung volumes after an increase in lung distension in pneumonectomized ferrets. J Appl Physiol 1989; 67: 1418-1421. 
4. Thurlbeck WM, Galaugher W, Mathers J. Adaptive response to pneumonectomy in puppies. Thorax 1981; 36: $424-427$.

5. Hsia CC, Herazo LF, Fryder-Doffey F, Weibel ER. Compensatory lung growth occurs in adult dogs after right pneumonectomy. J Clin Invest 1994; 94: 405-412.

6. Rannels DE, Karl HW, Bennett RA. Control of compensatory lung growth by adrenal hormones. Am J Physiol 1987; 253: E343-E348.

7. Watkins CA, Burkhart LR, Rannels DE. Lung growth in response to unilateral pneumonectomy in rapidly growing rats. Am J Physiol 1985; 248: E162-E169.

8. Rannels DE, White DM, Watkins CA. Rapidity of compensatory lung growth following pneumonectomy in adult rats. J Appl Physiol 1979; 46: 326-333.

9. Takeda S, Wu EY, Ramanathan M, Estrera AS, Hsia CC. Temporal course of gas exchange and mechanical compensation after right pneumonectomy in immature dogs. $J$ Appl Physiol 1996; 80: 1304-1312.

10. Takeda S, Hsia CC, Wagner E, Ramanathan M, Estrera AS, Weibel ER. Compensatory alveolar growth normalizes gasexchange function in immature dogs after pneumonectomy. J Appl Physiol 1999; 86: 1301-1310.

11. Scherle W. A simple method for volumetry of organs in quantitative stereology. Mikroskopie 1970; 26: 57-60.

12. Voswinckel R, Ziegelhoeffer $\mathrm{T}$, Heil M, et al. Circulating vascular progenitor cells do not contribute to compensatory lung growth. Circ Res 2003; 93: 372-379.

13. Fehrenbach A, Ochs M, Wittwer T, et al. Stereological estimation of the volume weighted mean volumes of alveoli and acinar pathways in the rat lung to characterise alterations after ischaemia/reperfusion. J Anat 1999; 194: 127-135.

14. Michel RP, Cruz-Orive LM. Application of the Cavalieri principle and vertical sections method to lung: estimation of volume and pleural surface area. J Microsc 1988; 150: 117136.

15. Ladekarl M. The influence of tissue processing on quantitative histopathology in breast cancer. J Microsc 1994; 174: 93-100.

16. Howard V, Reed MG, Royal Microscopical Society. Unbiased Stereology Three-Dimensional Measurements in Microscopy. Oxford, UK, BIOS Scientific Publishers in association with the Royal Microscopical Society, 1998.

17. Gundersen HJ, Jensen EB. Stereological estimation of the volume-weighted mean volume of arbitrary particles observed on random sections. J Microsc 1985; 138: 127-142.
18. Massaro GD, Massaro D. Formation of alveoli in rats: postnatal effect of prenatal dexamethasone. Am J Physiol 1992; 263: L37-L41.

19. Landesberg LJ, Ramalingam R, Lee K, Rosengart TK, Crystal RG. Upregulation of transcription factors in lung in the early phase of postpneumonectomy lung growth. $\mathrm{Am}$ J Physiol Lung Cell Mol Physiol 2001; 281: L1138-L1149.

20. Glaab T, Daser A, Braun A, et al. Tidal midexpiratory flow as a measure of airway hyperresponsiveness in allergic mice. Am J Physiol Lung Cell Mol Physiol 2001; 280: L565-L573.

21. Brown LM, Malkinson AM, Rannels DE, Rannels SR. Compensatory lung growth after partial pneumonectomy enhances lung tumorigenesis induced by 3-methylcholanthrene. Cancer Res 1999; 59: 5089-5092.

22. Leuwerke SM, Kaza AK, Tribble CG, Kron IL, Laubach VE. Inhibition of compensatory lung growth in endothelial nitric oxide synthase-deficient mice. Am J Physiol Lung Cell Mol Physiol 2002; 282: L1272-L1278.

23. Foster DJ, Yan X, Bellotto DJ, et al. Expression of epidermal growth factor and surfactant proteins during postnatal and compensatory lung growth. Am J Physiol Lung Cell Mol Physiol 2002; 283: L981-L990.

24. Rannels DE, Rannels SR. Compensatory growth of the lung following partial pneumonectomy. Exp Lung Res 1988; 14: 157-182.

25. Wandel G, Berger LC, Burri PH. Morphometric analysis of adult rat lung after bilobectomy. Am Rev Respir Dis 1983; 128: 968-972.

26. Laros CD, Westermann CJ. Dilatation, compensatory growth, or both after pneumonectomy during childhood and adolescence. A thirty-year follow-up study. J Thorac Cardiovasc Surg 1987; 93: 570-576.

27. Duebener LF, Takahashi Y, Wada H, Tschanz SA, Burri PH, Schafers HJ. Do mature pulmonary lobes grow after transplantation into an immature recipient? Ann Thorac Surg 1999; 68: 1165-1170.

28. Cagle PT, Langston C, Thurlbeck WM. The effect of age on postpneumonectomy growth in rabbits. Pediatr Pulmonol 1988; 5: 92-95.

29. Ochs M, Nyengaard JR, Jung A, et al. The number of alveoli in the human lung. Am J Respir Crit Care Med 2004; 169: 120-124.

30. Burri PH. Structural aspects of prenatal and postnatal development and growth of the lung. In: McDonald JA, Lenfant C, eds. Lung Biology in Health and Disease, Vol. 100. New York, Dekker Inc., 1997; pp. 1-32. 